\title{
SIGNIFICADO DA AVALIAÇÁO POR GRADUANDOS DURANTE UMA DISCIPLINA DE QUÍMICA GERAL - ESTAMOS EVOLUINDO?
}

\author{
Bruna da Silva Ganassin ${ }^{1}$ \\ Solange Wagner Locatelli ${ }^{2}$
}

\begin{abstract}
Resumo: A avaliação, um componente curricular elementar, se faz presente em toda a vida acadêmica dos estudantes, mas geralmente sua necessidade e importância muitas vezes não estáo evidentes para alunos. Neste trabalho, realizou-se uma análise qualitativa da percepção dos estudantes ingressantes que cursaram a disciplina Química Geral sobre a avaliação. Para isso, foi realizada de forma voluntária a aplicação de um questionário com perguntas que abrangiam diferentes aspectos da avaliação - do instrumental ao emocional. Os resultados levantados evidenciaram o forte caráter quantitativo que a avaliação ainda tem na formação dos estudantes, bem como a necessidade de repensar de forma crítica os instrumentos de avaliação, $o$ ato de avaliar e seu impacto na vida acadêmica.
\end{abstract}

Palavras-chave: Avaliação. Instrumentos de avaliação. Ensino de Química. Ensino Superior.

\section{MEANING OF THE EVALUATION FOR UNDERGRADUATED STUDENTS DURING A GENERAL CHEMISTRY DISCIPLINE - ARE WE EVOLVING?}

\begin{abstract}
Assessment, an elementary curricular component, is present throughout the academic life of students, but generally, its need and importance are often not evident to students. In this work, a qualitative analysis of the perception of evaluation expressed by first-year college students, who took the General Chemistry course, was carried out. For that, a questionnaire was applied voluntarily with questions that covered different aspects of the evaluation - from instrumental to emotional. The results showed strong quantitative character that evaluation still has in the training of students, as well as the need to critically rethink the assessment instruments, the act of evaluating and its impact on academic life.
\end{abstract}

Keywords: Evaluation. Assessment tools. Chemistry teaching. Higher education.

1 Graduada no BC\&T; Graduanda em Química; Universidade Federal do ABC; Discente.

2 Doutora pela USP; Docente no Centro de Ciências Naturais e Humanas, Universidade Federal do $\mathrm{ABC}$. 


\section{INTRODUÇÃO}

O sistema educacional brasileiro visa formar cidadãos que contribuam para a sociedade e exerçam sua cidadania com consciência de seus deveres, direitos e que estejam preparados para enfrentar os desafios da modernidade. Para isso, disponibiliza de forma universal e gratuita para toda sua população o ciclo básico de educaçáa que se encontra alicerçado de acordo com as Diretrizes Curriculares Nacionais da Educação Básica e com a Base Nacional Comum Curricular, BNCC (2018, p.7), que propóem uma "construção de uma sociedade justa, democrática e inclusiva”.

Essa aprendizagem precisa estar de acordo com as decisões curriculares e didático-pedagógicas das Secretarias de Educação (BNCC, 2018, p.15), estar comprometida com valores que estimulem a curiosidade intelectual, a criatividade, o entendimento e utilização de diferentes linguagens, símbolos e tecnologias. E empenhada em enaltecer equidade e aspectos biopsicossociais, assim como a diversidade, o senso crítico, a responsabilidade social, a cooperação e a ética (BNCC, 2018).

De acordo com Bizelli (2015), a escola é o cenário de constante reinvenção, no qual as políticas oficiais de educação são testadas, colocadas à prova, frente a realidade desafiadora de seu cotidiano. A promoção da educaçáo perpassa por problemas que estão ligados à falta de investimento na educação, desvalorização do espaço escolar e dos professores, questóes de acesso, permanência e evasão dos estudantes nas escolas, conflitos internos gerados pela heterogeneidade dos alunos e falta de integração com a comunidade em seu entorno.

Ainda assim, dentro do ambiente escolar é esperado que os estudantes encontrem um espaço de acolhimento (ALMEIDA, 2015), que os possibilitem adquirir competências necessárias para ler e compreender textos criticamente, fazer uso de símbolos e códigos com apreciação de seus significados e que sejam estimulados a manipular tecnologias que os ajudem a estar atualizados com as mudanças e inovaçôes que ocorrem no mundo globalizado, além de valores éticos que contribuam para sua vivência na sociedade, como respeito à diversidade, solidariedade, desenvolvimento sustentável e preocupaçáo em acabar com as desigualdades (DIAS; PINTO, 2019).

O papel da educação perpassa pelo desenvolvimento individual e coletivo dos estudantes na intenção de compreender fatores sociais, ambientais, históricos, econômicos e políticos. Para orientar essas descobertas cabe ao professor desmistificar conteúdos e instigar os alunos a pensar de maneira criativa, ajudandoos a desenvolver seu raciocínio lógico, disciplina e organização (GADOTTI, 2000), sobretudo com vistas à construção de seu conhecimento.

Desse modo, a prática docente precisa estar atenta às necessidades e dificuldades dos estudantes dentro da sala de aula, uma vez que a falta de autonomia e ou letramento científico deficiente podem gerar obstáculos à formação. Outro aspecto que deve ser levado em consideração são as diferenças entre os estudantes 
dentro da sala de aula. Haverá indivíduos com interesses distintos que aprenderão em ritmos diferentes, e que trarão à prática docente o desafio de adaptar seus métodos para o melhor entendimento dos alunos (MALAFAIA; RODRIGUES, 2011).

Em seu planejamento educacional o docente precisará equilibrar aspectos reguladores, com estímulos que aproximem os estudantes e os façam querer participar da aprendizagem, de modo que percebam a importância de refletir sobre o que lhes foi ensinado (NÖRNBERG; FORSTER, 2016). Assim, o professor náo demonstra apenas seu conhecimento técnico sobre um determinado tema, mas também que consegue ensiná-lo ao harmonizar os saberes conceituais e pedagógicos. Ao integrar esses conhecimentos, o docente consegue auxiliar na construção do conteúdo científico para a linguagem dos estudantes, colhendo suas concepçôes prévias e estabelecendo novos significados. Deste modo, o cotidiano em sala de aula ganha uma nova interpretaçáo que contribuirá para que a edificação de conhecimento seja efetiva (ALTARUGIO; LOCATELLI, 2018).

Entretanto é importante salientar que a ruptura de ideias pré-concebidas ou de aprendizagens anteriores não é um processo fácil. É exigido do professor que ele consiga lidar com questôes problematizadoras de maneira dinâmica, ao mediar discussôes e lançar dúvidas que possam levar os estudantes a uma nova concepção desse aprendizado, ao romper barreiras antes invisíveis com estabelecimento de novas ideias. Ao aproximar os estudantes da prática docente, é aberta uma porta para o diálogo entre professores e alunos, o que contribui para a diminuição de atritos em sala de aula (NÖRNBERG; FORSTER, 2016).

Embora o ensino exija maior flexibilidade e constante reflexão por parte do docente sobre a maneira e a qualidade com que suas aulas devem ser conduzidas, de modo que aprendizagem legada aos estudantes os acompanhe por toda a vida e os incentive a busca por soluçôes para problemas existentes de uma maneira inovadora e consciente (NÖRNBERG; FORSTER, 2016), a prática docente não pode fugir de certos paradigmas estabelecidos no processo educacional, e isso se torna muito evidente quando se analisa a avaliação (ALTARUGIO; LOCATELLI, 2018). Portanto, é imprescindível discutir o papel da avaliaçáo e como esta pode impactar a prática docente, assim como a percepção dos alunos.

\section{ALGUMAS CONSIDERAÇÓES SOBRE A AVALIAÇÃO}

A avaliação faz parte da prática docente, mas a discussão sobre seu papel e importância no processo pedagógico desenvolvido pelos docentes e a percepção dos discentes é algo bastante atual. Isso porque, tradicionalmente o processo de avaliação visava apenas a atribuiçấo de notas aos estudantes de maneira isolada e sua promoção de série, inspirado em uma forma de ensino tecnicista (MACENO; GUIMARẢ̉ES, 2013).

Para Zabala (1998), a avaliação tradicional é concebida como uma ferramenta sancionadora e qualificadora, na qual os estudantes são testados de maneira 
classificatória de acordo com critérios e objetivos mínimos pré-estabelecidos pelo sistema de ensino.

O sistema de ensino por sua vez propóe que a avaliaçáo seja projetada nos alunos, ao selecioná-los para detectar quem está apto a progredir de série até chegar ao nível superior. De acordo com Alavarse (2013), essa forma de avaliação passou a se caracterizar como protocolo de progresso ao qual os estudantes sáo submetidos, que difunde uma visão limitada de sua trajetória escolar e reforça o estereótipo da meritocracia, ao promover sentimentos de exclusão nos alunos e relegar a importância da avaliação.

Zabala (1998) acreditava que, para transformar esse cenário, era necessário refletir sobre a condução da prática pedagógica e o progresso de seus atores (estudantes, grupo de estudantes e professores) de maneira individual, coletiva, bem como a interação entre eles.

Ao fugir da concepção tradicional, Zabala (1998) nos alerta para a função social do ensino, que ao apresentar o foco no desenvolvimento integral dos estudantes estimula uma mudança nas conjecturas da avaliação. Nesse momento, entra em análise a maneira como o docente ensina e como o estudante aprende e o porquê a avaliaçáo se faz necessária. Assim, ganham espaço na avaliaçáo os conteúdos conceituais, procedimentais e atitudinais para, segundo Zabala, (1998, p. 197) promover "as capacidades motoras, de equilíbrio e de autonomia pessoal, de relação interpessoal e de inserção social".

Perrenoud (1998) também destaca a importância do desenvolvimento dessas capacidades devido a prática avaliativa ainda apresentar um forte caráter comparativo, na qual a performance de um estudante define a dos demais, e como isso implica a perda do propósito da avaliação e desconsidera as habilidades individuais dos alunos.

Essa mudança na forma de avaliar promove o ensino de forma que o potencial de cada aluno se desenvolva ao máximo. Para isso, a avaliação precisará deixar de ser meramente quantitativa e classificatória, ao invés disso, deverá ser centrada no processo de aprendizagem (ZABALA, 1998). Entretanto, esse tipo de mudança está sujeito a uma série de dificuldades que vão desde a hesitação em repensar suas práticas e forma de avaliar, a maneira como o currículo está organizado, até a falta de cooperaçấo entre professores e estudantes (PERRENOUD, 1998).

Conforme Alavarse (2013), para transformar esse cenário é preciso refletir sobre a importante função da avaliação no processo pedagógico, e dialogar a respeito das formas de avaliação disponíveis, como renová-las e essencialmente questionar o papel das provas, que com frequência são utilizadas como principal ou único instrumento de avaliação.

Ao romper com a visão uniformizadora do ensino, é estabelecida uma relação com as concepçóes prévias por meio de uma avaliaçáo inicial, na qual se entende as singularidades dos alunos, assim como a melhor maneira de instruí-los. Dessa 
forma, será possível estabelecer atividades e intervençóes que favoreçam uma aprendizagem formativa (ZABALA, 1998).

De acordo com Perrenoud (1998), a avaliaçáo formativa se refere a uma avaliação contínua, na qual os professores, por meio de observação e orientação sistemática dos estudantes, percebem seu desenvolvimento educacional e redefinem suas açóes pedagógicas de maneira crítica com o objetivo de otimizar seu aprendizado. Assim, por meio de uma avaliação formativa é possível inserir um processo de regulaçáo de aprendizagens na vida dos alunos, de modo a abranger novas concepçôes por meio de diversas intervençôes didáticas (PERRENOUD, 1998).

Dentro desse processo, é essencial lembrar que a sala de aula não é um ambiente homogêneo e que não existem resultados absolutos. É necessário destacar que a aprendizagem, bem como a avaliação dessa aprendizagem, segundo Luckesi (2000, p. 1) devem ser "amorosas, inclusivas, dinâmicas e construtivas". Luckesi (2000) também ressalta que a avaliação não pode ser vista com neutralidade e que a análise e a tomada de decisão estão no centro do processo avaliativo.

Então, será necessária a adequação da prática pedagógica de acordo com as necessidades de cada aluno para a sua adaptaçáo a novas ideias, o que torna a avaliação de seu aprendizado reguladora (ZABALA, 1998). O ensino regulador em sua proposta, enfatiza a importância da orientação dos alunos pelo professor por meio do processo dinâmico de mediaçáo. Assim, é possível que ocorra a reorientação da aprendizagem de modo que se consiga levar os alunos a pensar e reestruturar suas concepções de aprendizagem, desenvolvendo sua autorregulação no processo de aprendizagem (PERRENOUD, 1998).

A evoluçáo do desempenho do estudante, que compóe a avaliação de todo o seu percurso acadêmico, permitirá saber se serão necessárias modificaçóes no seu processo de aprendizagem. A partir desses questionamentos e preocupaçôes com o ato de ensinar e de aprender é que se percebe o papel da avaliação, sua importância no que diz respeito ao progresso dos estudantes e um melhor desempenho da prática educativa por parte dos professores (ZABALA, 1998).

Para a avaliação obter um caráter mais amplo, será necessário verificar se a aprendizagem engloba aspectos que não se limitam a conteúdos factuais e que estes ao serem ensinados, sejam usados para ancorar novos conceitos e concepçóes mais abrangentes (ZABALA,1998). Nessa perspectiva, torna-se fundamental a inclusão do ensino da história da ciência, para possibilitar melhor compreensão do conteúdo ensinado, ao desmistificar aspectos individualistas ou imediatos, principalmente no que diz respeito ao estudo de disciplinas como a Química. Segundo Vidal e Porto (2014) o ensino da história da ciência consegue atribuir um papel sociológico à ciência e evidencia concepçóes de difícil compreensão. A história do ensino pode estar presente em diferentes métodos de ensino, tais como, a produção de textos que façam um paralelo entre ciência e história, e estudos de caso histórico que levantem aspectos históricos e sua relação com a ciência (VIDAL; PORTO, 2014). 
Alinhar conteúdos da história da ciência na elaboração das avaliações exigirá dos professores, uma redobrada atenção ao fazer essa avaliação, pois é necessário que ela esteja adequada a compreensão dos estudantes. Uma vez com as respostas dessa avaliação, o professor poderá reorientar os rumos de sua prática pedagógica, de modo que ela seja coerente, inclusiva e eficiente (ALAVARSE, 2013).

Na prática pedagógica, ao que concerne à avaliação e os conteúdos conceituais, se discute a limitação que estes podem apresentar caso sua compreensão não seja elaborada com maior profundidade. De acordo com Zabala (1998) é necessário que conteúdos conceituais possam ser integrados à interpretação dos conhecimentos, para que essa náo se torne simplista.

No que implica os conteúdos procedimentais, compreende-se a avaliação a partir da aplicaçáo dos conteúdos aprendidos. É preciso que o estudante questione qual é o emprego daquele conhecimento e como ele pode ser aplicado (ZABALA, 1998). Dessa forma, a aprendizagem se tornará consciente também por parte dos estudantes. Assim, o desenvolvimento de suas competências e qualidades serão mais nítidas em sua avaliação (LUCKESI, 2000).

Ao professor é proposta a avaliação sistemática do desempenho, por meio da observação da performance dos estudantes em debates, pesquisas e outras atividades realizadas em sala de aula. Esses conteúdos atitudinais propóem a reavaliação de paradigmas, ao náo permitir a sua análise a partir de dados quantitativos. Esse tipo de avaliação nasce do estabelecimento do que é importante para os alunos, bem como por meio de situaçóes conflitantes entre eles, e sua capacidade de atuação frente a esses dilemas. Neste caso, a figura do professor exerce por meio da observação sistemática dos alunos, um papel mediador, ao ajudá-los a chegar nas melhores soluçôes com base em propostas educativas (ZABALA, 1998).

Segundo Luckesi (2000), dentro da sala de aula, a avaliação deve proceder de modo que o estudante se sinta acolhido, para que o processo avaliativo possa ocorrer de maneira adequada. Uma vez que isso acontece, novas relaçóes, por ora de conflito e contradiçôes, se estabelecem no diálogo da prática educativa.

Esses esforços para transformar a forma como a avaliação tradicional é aplicada, também já haviam sido destacados por Maldaner (2013, p.254), que evidenciava a urgência em "desrotinizar" a prática pedagógica para que os professores possam valorizar a produção, o raciocínio que o estudante desenvolveu para fazer uma tarefa, principalmente no que diz respeito ao ensino de disciplinas como a Química. Para tanto, os professores também precisam questionar, se a forma como aprenderam a avaliar durante sua graduaçáo contempla o ensino e a avaliaçáo em sua integralidade ou se apenas são a replicação irrefletida de modelos de avaliação tradicionais (NOGARO; ECCO, 2015).

Para Maldaner (2013), também é necessário que se avalie todo o processo de ensino e aprendizagem para que, dessa forma, seja feita a análise de seu progresso. Para isso, Maldaner (2013) também propunha que fossem dados aos alunos a oportunidade de serem avaliados por meio de relatórios de aula e que as questôes de 
provas fossem elaboradas de forma a evitar a transposiçáo automática de conteúdo dados em sala de aula para o papel.

Segundo Maldaner (2013), a modificação na forma de avaliar permite não apenas uma avaliação da compreensão dos estudantes sobre um tema, mas também dá a chance ao professor de pensar sobre a própria prática docente e seus resultados, no que tange às mudanças pedagógicas, concepçóes epistemológicas e planejamento. Este último, balizado em sistematizar um plano de ensino didático-pedagógico coerente para conseguir uma aprendizagem efetiva por parte dos estudantes, que poderá ser averiguada por diferentes instrumentos de avaliação (NOGARO; ECCO, 2015).

Para assegurar mudanças na forma como a aprendizagem é realizada, tornase importante o desenvolvimento da metacognição tanto por parte dos professores como dos estudantes. A metacognição pode ser compreendida sob a égide de dois elementos centrais, que de acordo com Ribeiro (2003, p.110) seriam "o conhecimento sobre o conhecimento" e o "controle ou autorregulação (capacidade para avaliar a execução da tarefa e fazer correções quando necessário)". No caso dos estudantes, esses dois aspectos mostram-se fundamentais para pensem e repensem seu aprendizado, o que possibilitará a concatenação de conteúdos de diferentes áreas para edificar o conhecimento sobre um determinado assunto adequadamente. Segundo Locatelli (2014, p. 24-25), desenvolve-se como "uma série de processos envolvendo o monitoramento e o repensar dos próprios conhecimentos, levando gradativamente a um aumento na autonomia do estudar e aprender".

No contexto da avaliação, a metacognição propóe o desenvolvimento e evoluçáo da maneira como se avalia o aprendizado, se o estudante consegue, no decorrer de seus estudos, se atribuir maior responsabilidade no seu processo de aprendizagem. Essa relação de autorregulação cognitiva perpassa toda a vida acadêmica dos estudantes, e apenas o domínio dessa habilidade ajuda o estudante a desenvolver a autonomia em relação aos seus estudos, e assim modifica sua relação com a aprendizagem e a avaliação (LOCATELLI, 2014).

Ao pensar em uma maior independência por parte dos alunos, é difícil não pensar nas dificuldades que os mesmos apresentam em algumas disciplinas, como a Química, cuja a avaliação se torna um desafio para os estudantes devido aos vários níveis de compreensão que os fenômenos apresentados na matéria exigem. Os alunos muitas vezes têm dificuldade de romper com suas concepções prévias, que nem sempre estão alinhadas com os conceitos científicos, e muitas vezes estáo repletas de generalizaçóes e animismos, o que torna sua mudança conceitual mais difícil e demorada (TREAGUST; DUIT; NIESWANDT, 2000).

Outros fatores que costumam prejudicar a aprendizagem dos estudantes em Química referem-se à dificuldade em realizar abstraçóes para entender a natureza particulada da matéria e os modelos utilizados para explicá-la, bem como problemas em compreender e relacionar representaçóes macroscópicas, submicroscópicas e simbólicas. Devido a tamanha complexidade, cabe ao professor de Química dedicar muita atenção aos conhecimentos prévios dos estudantes e buscar várias formas de 
avaliá-lo de modo que os alunos se aproximem da disciplina mesmo sabendo que sua compreensão não é intuitiva (TREAGUST; DUIT; NIESWANDT, 2000).

Dessa forma, o presente artigo tem por finalidade levantar quais são as concepçôes que graduandos, cursando uma disciplina de química geral no $1^{\circ}$ ano de ingresso numa universidade pública, têm sobre a avaliação.

\section{METODOLOGIA}

A metodologia utilizada para o presente artigo foi a realizaçáo de uma pesquisa qualitativa descritiva, com a finalidade de compreender a percepçáo dos estudantes sobre avaliaçáo, bem como o impacto que ela tem em suas vidas acadêmicas (PARANHOS et al., 2016).

Participaram da pesquisa 3 alunos e 7 alunas, designados por A1 a A10 para garantir o anonimato dos participantes. Todos os estudantes entrevistados estáo no 1. ${ }^{\circ}$ ano de graduação e matriculados na disciplina de Química Geral ofertada em uma Universidade Federal, com média de idade por volta de 17-24 anos.

A Universidade em questáo, está localizada no estado de São Paulo. Conta com um corpo docente formado exclusivamente por professores doutores com atuação simultânea nas áreas de docência, pesquisa, extensão, comunicação e divulgação científica.

O ensino proposto pela universidade é abrangente e interdisciplinar. Todos os seus ingressantes cumprem um ciclo básico de disciplinas voltadas para as áreas de ciência e tecnologia ou ciências e humanidades e após essa etapa estáo aptos a dar continuidade em seu curso específico para obter um diploma de bacharel, licenciado, engenheiro de sua preferência ou sair para o mercado de trabalho preparados para enfrentar os mais diversos desafios.

A averiguação do presente estudo ocorreu por meio da aplicação de um questionário online contendo dez questôes (quadro 1), totalizando 10 questionários respondidos. Vale ressaltar que os alunos e alunas foram orientados que se tratava de uma pesquisa acadêmica e de participação voluntária. Os questionários foram respondidos individualmente e os resultados coletados serão apresentados no quadro 1:

Quadro 1. Representação do questionário aplicado aos estudantes

\begin{tabular}{|l|l|}
\hline & Perguntas \\
\hline $\mathbf{1}$ & Para você o que é a avaliação? \\
\hline $\mathbf{2}$ & Quais as formas de avaliação você conhece? \\
\hline $\mathbf{3}$ & Você acredita que a avaliação contribui para o seu aprendizado? Justifique. \\
\hline $\mathbf{4}$ & $\begin{array}{l}\text { Você percebe muita diferença entre as formas de avaliação do ensino médio e do ensino } \\
\text { superior? Com 0 representando nenhum grau de concordância e } 4 \text { o máximo grau de con- } \\
\text { cordância. }\end{array}$ \\
\hline
\end{tabular}




\begin{tabular}{|l|l|}
\hline & Perguntas \\
\hline $\mathbf{5}$ & O que você acha da prova como forma de avaliação? \\
\hline $\mathbf{6}$ & Ao fazer uma avaliação, você se sente: Confiante ou inseguro? Justifique. \\
\hline $\mathbf{7}$ & $\begin{array}{l}\text { Em uma avaliação, o professor aponta suas dificuldades em determinado conteúdo. Você } \\
\text { revisita esse conteúdo para sanar suas dificuldades/dúvidas? Como respostas, às alternativas } \\
\text { possíveis eram: Sim, sempre; sim, mas apenas se for essencial para a compreensáo dos próxi- } \\
\text { mos tópicos; às vezes e nunca. }\end{array}$ \\
\hline $\mathbf{8}$ & $\begin{array}{l}\text { Hoje no ensino superior como são suas notas comparadas com as do ensino médio? Como } \\
\text { respostas, às alternativas possíveis eram: Melhores; Iguais e Piores. }\end{array}$ \\
\hline $\mathbf{9}$ & $\begin{array}{l}\text { A adoção de outros instrumentos de avaliação (trabalhos, resenhas, portfólio, entre outras) } \\
\text { mostram-se mais eficientes no processo de aprendizagem? Justifique. }\end{array}$ \\
\hline $\mathbf{1 0}$ & $\begin{array}{l}\text { O portfólio te ajuda no aprendizado? Com } 0 \text { representando nenhum grau de concordância } \\
\text { e } 4 \text { o máximo grau de concordância. }\end{array}$ \\
\hline
\end{tabular}

Fonte: Perguntas elaboradas pelas autoras.

\section{Análise dos dados}

Com relação à pergunta 1 (quadro 1), as respostas apontaram para dois caminhos, sendo o primeiro que a avaliaçáo era uma forma de determinar o conhecimento dos estudantes, como pode-se observar na fala da aluna A2:

No campo educacional, acredito que seja uma forma de verificar o aproveitamento dos alunos em relação à disciplina. Uma forma de medir como vai a relação aluno/professor/aprendizagem, além de servir de base para estabelecimentos de estratégias educacionais conforme os resultados obtidos (Aluna A2).

Por outro lado, a avaliação ainda é representada com um forte caráter quantitativo na aprendizagem, como relatado nas falas dos alunos A5: "Uma maneira de quantificar o que eu sei de determinada matéria" e A1: "É um método de aferir o nível de conhecimento sobre algum assunto".

A pergunta 2 (quadro 1) buscou saber a quais tipos de avaliação os participantes da pesquisa estavam familiarizados. Alguns alunos alegaram estar familiarizados com apenas um tipo de avaliação e suas modalidades, como os estudantes A3: "Prova escrita e oral". Outros incluíram formas mais colaborativas de avaliação em seus depoimentos, é o caso da aluna A9: "Provas, trabalhos e seminários". Entretanto, alguns estudantes descreveram suas respostas com diferentes formas de avaliação, representadas nas falas das alunas A1: "Prova sem consulta, trabalho, portfólio, atividades com consulta ou prazos longos" e A8: "Prova, trabalhos em grupo, seminários, portfólio, artigos, redação".

Questionados sobre a contribuição da avaliação para o aprendizado na pergunta 3 (quadro 1) os resultados mostraram-se bastante divididos, alguns estudantes acreditam que a aprendizagem é prejudicada diante da cobrança e 
expectativa por resultados que podem mudar de acordo com o tipo de avaliação, como podemos observar nas falas dos alunos A4: "Acredito que sim, porém depende da forma que essa avaliação é aplicada" e A7: "Depende, algumas matérias você apenas se empenha pois precisa de nota", da mesma forma que o aluno A6 que ainda ressalta a importância do resultado que se espera alcançar ao fim do processo de avaliação: "Em partes. Na minha opinião a avaliação tira a magia da disciplina, a vontade de aprender, e a transforma na necessidade de mostrar em números. Muitas vezes você não estuda para aprender a matéria e sim para ir bem na avaliação" (Aluno A6). Outros mostraram-se otimistas, pois acreditam que a avaliaçáo contribui para descoberta de pontos nebulosos em seus estudos, o que permite uma autoavaliação e redirecionamento do seu aprendizado, exemplificado pela fala da aluna A8: "Sim, pois com a avaliação eu posso ver aquilo que ainda não compreendi muito bem para revisar posteriormente e isso é uma coisa que me ajuda a estudar".

Quando perguntados se encontram muita diferença entre as formas de avaliação do ensino médio e do ensino superior na pergunta 4 (quadro 1), as respostas foram fornecidas em uma Escala de Likert com zero representando o nenhum grau de concordância e 4 o máximo grau de concordância. As respostas foram diversificadas, o que pode ser uma consequência da heterogeneidade da turma que possui estudantes vindos de diferentes regióes do país e que dificilmente dispóem das mesmas condiçóes sociais e econômicas, o que pode refletir em uma consequente falta de equidade entre os participantes do questionário, como demonstrado pela figura 1 :

Figura 1. Representação da resposta obtida a partir Escala de Likert para a questão 4: Você percebe muita diferença entre as formas de avaliar do ensino médio e do ensino superior?

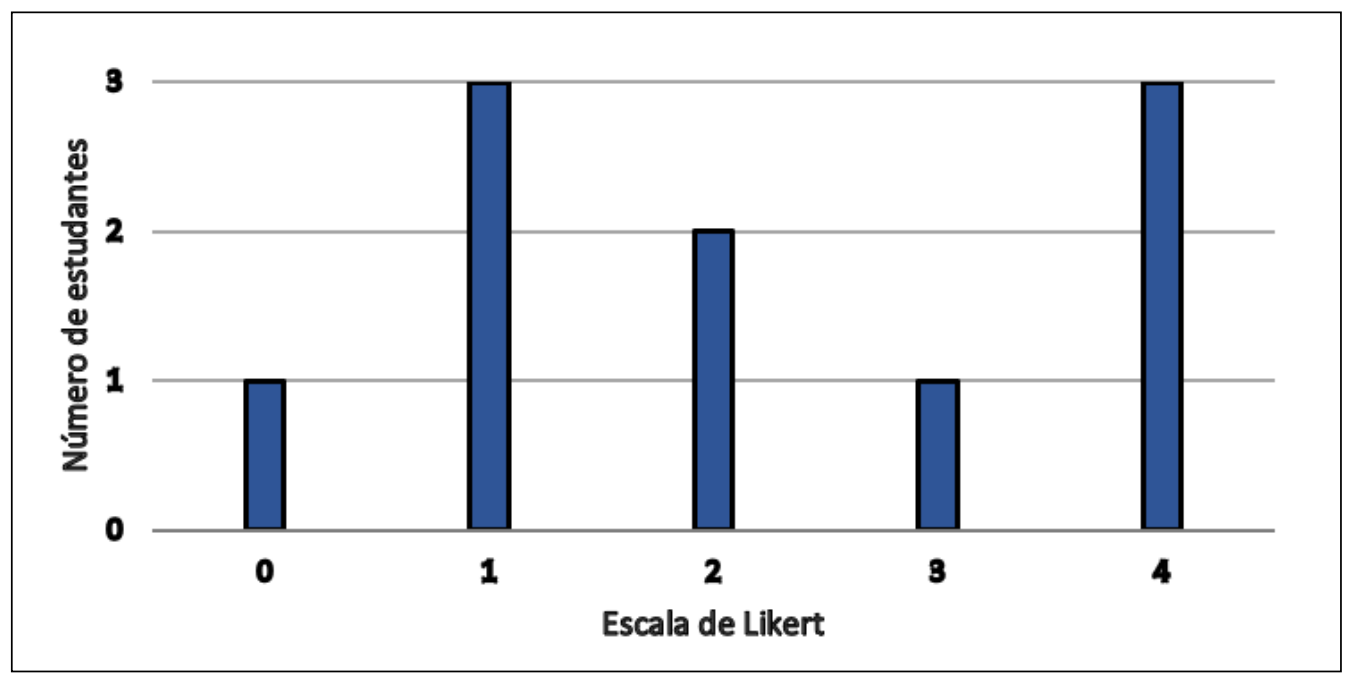

Fonte: Autoras. 
Indagados sobre o que acham das provas como forma de avaliação na questáo de número 5, alguns estudantes acreditam que a prova serve como estímulo aos estudos, os ajudam a estudar com mais empenho como descrito na resposta da estudante A5 que também exalta o fato de que a prova não deve ser o único instrumento de avaliação: "Acho que é um método legal, mas eu acredito que não deva ser o único". Entretanto a maioria salienta que a prova não reflete o conhecimento dos alunos de maneira integral, e deixa de respeitar as singularidades dos estudantes, expondo suas limitaçóes, uma vez que para os estudante também devem ser considerados aspectos emocionais no momento do teste, o que dificulta um melhor desempenho por parte dos alunos como descreve a aluna A3: "Não acho um método viável, sempre fico nervosa por dias antes e acabo náo dando meu melhor, fazendo de qualquer jeito "pra acabar logo o estresse"”.

Outro aspecto negativo levantado pelos estudantes, está na limitaçáo do conhecimento ao ato de decorar e o fato de uma prova com poucas questóes náo ser capaz expressar o aprendizado dos alunos em um período de tempo longo de acordo com a aluna A8: "Na maioria das vezes, a prova não é o melhor método avaliativo já que em um dia você deve mostrar o que aprendeu em um longo período de tempo, com poucas questóes".

No que diz respeito aos aspectos emocionais, a maioria dos alunos relataram sentirem-se inseguros ao fazer uma avaliação, como resposta à questáo 6 (quadro 1), e que isso, infalivelmente, impacta em suas notas de acordo com a resposta do aluno A4: "Totalmente inseguro, me sinto muito pressionado e às vezes travo totalmente. Um desastre". Apesar de acreditarem que a afinidade com a disciplina pode fazer diferença para diminuir essa insegurança como relata a aluna A2: "Depende. Temas que eu gosto, me sinto um pouco mais confiante, já que gosto de pensar e falar sobre o assunto. Temas que não tenho interesse, a prova se torna um peso" e mesmo muitas vezes preparados para realizar uma avaliação, a carga emocional depositada nesse momento, faz com que os alunos se sintam pressionados, logo acabam por esquecer detalhes ou informaçóes que seriam relevantes para uma explicação como descreve a aluna A1: "Insegura, mesmo que tenha estudado e esteja preparada, há uma grande ansiedade e tensão, por conta da pressão em fazer a prova em determinado tempo e insegurança quanto aos resultados". Saem da prova com a sensação de que não fizeram o suficiente.

Outro aspecto levantado pelos estudantes é a elaboraçáo de provas pelos docentes com um nível de exigência incompatível com as aulas e atividades oferecidas para direcionar seus estudos para uma avaliação, o que também gera frustração e um desempenho abaixo do esperado como descrito pela aluna A8: "Acredito que depende da afinidade que o aluno tem com a matéria e também do nível de prova do professor, mas acredito que na maioria das vezes os alunos se sintam inseguros".

As avaliaçóes podem ser utilizadas como poderosas ferramentas para evidenciar as dificuldades que os estudantes apresentam em um determinado tema de uma matéria e também nortear o docente sobre o quão eficiente tem sido a aplicação de suas concepçôes de ensino e aprendizagem. Mas, uma vez detectadas essas falhas no 
conhecimento, a maioria dos alunos declarou como resposta à questão 7 (quadro 1) que só revisita esse conteúdo para sanar suas dúvidas se isso for essencial para a compreensão dos próximos tópicos do assunto, o que pode desencadear um efeito cascata dessas dificuldades, ao tornar a disciplina incompreensível, culminando na reprovação do estudante.

A reverberação de todos os aspectos levantados é a diferença que os estudantes sentem ao comparar suas notas com as que possuíam no ensino médio. Logo, como resposta à questão 8 (quadro 1) a maioria dos alunos alegaram que suas notas pioraram, o que pode ser uma consequência do maior grau de exigência do nível universitário.

Nesse processo, os estudantes descrevem de maneira absoluta na questáo 9 (quadro 1) que a adoção de outros instrumentos de avaliação se mostra mais eficiente no processo de aprendizagem como descreve o aluno A10: "Sim. Tais instrumentos fazem com que o aluno tenha que tomar relativamente mais iniciativa, além de gerarem um maior diálogo do assunto entre os indivíduos, facilitando o processo de aprendizagem". Eles se sentem estimulados a aprender, pois conseguem se expressar de modo a relatar melhora de suas concepçóes de acordo com a fala dos alunos A8: "Sim, primeiro que quando os professores propóem novos métodos de ensino, os alunos se sentem mais motivados e assim também há mais canais para o aprendizado, náo apenas a aula monótona e a prova" e A6: "Sim, pelo menos comigo e no especial os portfólios me mantém muito mais engajado na matéria e evitam que eu somente estude na última hora para a prova".

Mesmo se tiverem dificuldade com o tema, acreditam que o docente consegue acompanhar o desenvolvimento dos alunos encorajando-os, ajudando-os a sanar dúvidas, a refletir sobre suas aprendizagens e criar uma disciplina de estudos, o que reflete em uma maior autonomia como articula a aluna A2: "Sim, além de acompanhar o desenvolvimento do aluno, ajuda a despertar outras habilidades e dá uma oportunidade a esse aluno de aprender e demonstrar seu aprendizado da forma que melhor se encaixa ao seu perfil e sua realidade".

É importante destacar que os alunos participantes da pesquisa, fizeram uso do portfólio, uma metodologia ativa, como alternativa aos instrumentos tradicionais de avaliação durante a disciplina de Química Geral. Esses portfólios consistiam da entrega semanal das anotações feitas em casa, com a resolução dos exercícios e principalmente com uma autoavaliação da aula, em que eles tinham que localizar suas dificuldades, bem como propor açóes para superá-las.

Assim, questionados especificamente sobre um desses instrumentos alternativos de avaliação, o portfólio, ferramenta a qual os estudantes já estavam familiarizados, perguntou-se na questão 10 (quadro 1) se eles se sentiam ajudados por esse instrumento, sendo as respostas fornecidas também por uma Escala de Likert com zero representando o nenhum grau de concordância e 4 o máximo grau de concordância (figura 2). 
Figura 2. Resposta obtida a partir Escala de Likert para a questáo 10: O portfólio te ajuda no aprendizado?

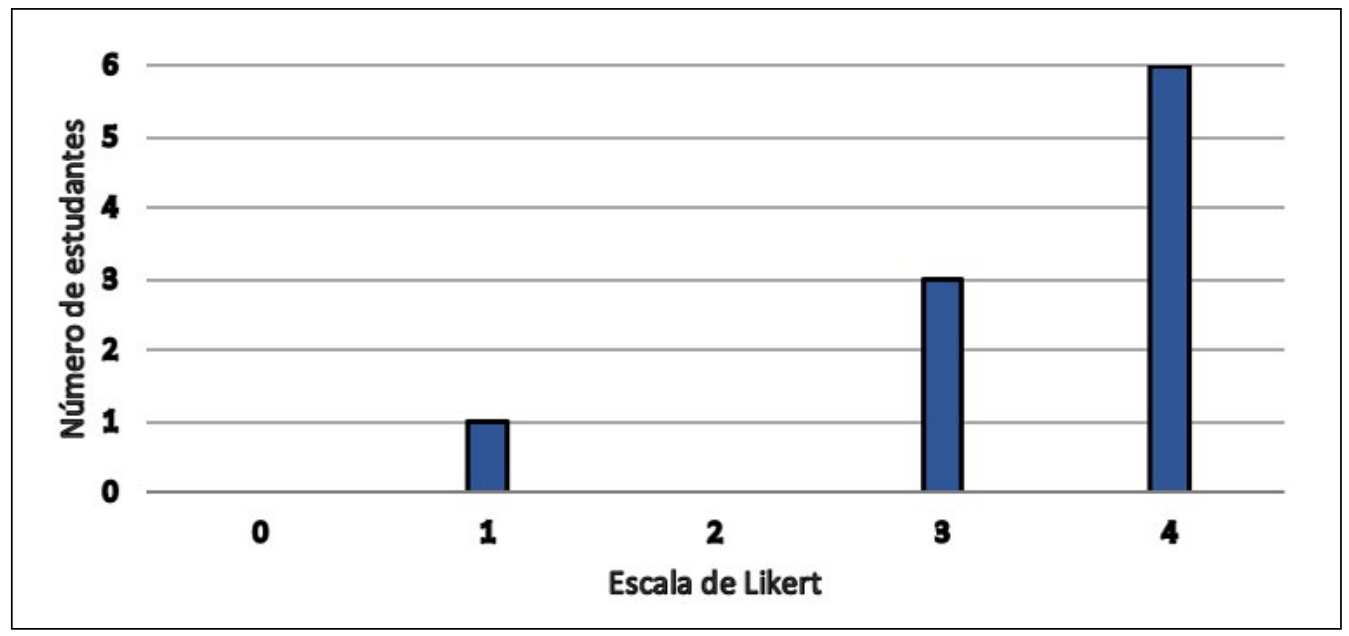

Fonte: Autoras.

As respostas fornecidas apontam uma contribuição positiva do portfólio na aprendizagem dos alunos.

\section{DISCUSSÃO}

Os resultados da pesquisa com os estudantes, corroboram com a inquirição de Ramos e Argolo (2018) que descrevem que a percepção da avaliação por parte dos discentes são muito distintas entre si, algumas positivas, outras desfavoráveis em consequência de sua trajetória acadêmica. Esse resultado realça como a mudança dos paradigmas educacionais na avaliação ainda tem um forte caráter tecnicista e classificador exemplificado por provas e testes somativos (RAMOS; ARGOLO, 2018).

A análise das respostas dos estudantes sinaliza que a evolução da avaliaçáo ainda ocorre de maneira lenta e muitas vezes descontínua, o que é demonstrado em suas falas quando comparam com as formas de avaliar em outras disciplinas ou até mesmo com o ensino médio (MARINHO; CALCAGNO; DA SILVA, 2018). De modo geral, as respostas demonstram que, por mais que sejam utilizadas ferramentas diferentes para testar as suas aprendizagens, os alunos ainda parecem presos a ideia da avaliação como um instrumento quantificador principalmente no que diz respeito a prova como instrumento de avaliação (ZABALA, 1998).

Segundo Heberle (2014), esta percepçáo negativa da avaliação está ligada à falta de reflexão sobre a avaliação, no que tange sua elaboração e aplicação em sala de aula. Para a edificação de uma nova rotina pedagógica, é necessário repensar o papel da avaliação e seu significado por parte do professor, assim como, de todo corpo docente redesenhar o currículo com objetivos mais qualitativos. Nesse processo, 
para estimar as dificuldades dos alunos, é imprescindível um diálogo aberto que contemple suas demandas (HEBERLE, 2014).

Os alunos também mencionam em mais de um momento, que a prova não possibilita a avaliação do conteúdo de maneira integral. Em contrapartida, os estudantes parecem ter uma clara percepção da importância da avaliaçáo formativa em sua dinâmica escolar, uma vez que a avaliaçáo formativa permitirá a observação e orientação sistemática por parte dos professores (PERRENOUD, 1998), contribuindo para sua autorregulação cognitiva ao desenvolver sua autonomia em relação aos seus estudos.

As respostas dos estudantes evidenciaram a necessidade de que ocorram mudanças mais efetivas na forma de avaliar, com a inserção de diferentes metodologias que ajudem a determinar a evolução da aprendizagem dos alunos, bem como despertem nos docentes, novas maneiras de avaliar explorando conteúdos tecnológicos e lúdicos que o ajudem a mediar a aprendizagem (MARINHO; CALCAGNO; DA SILVA, 2018).

Neste contexto, a inserção de outras ferramentas de avaliação pode possibilitar a oportunidade dos alunos expressarem seu potencial e assim contribuir para a diminuição de suas inseguranças (LUCKESI, 2000). No que diz respeito ao aspecto emocional, é relevante salientar que cabe ao professor promover o engajamento do aluno com a aprendizagem na disciplina, ao torná-la compreensível para os alunos e ao estar acessível às suas demandas (LUCKESI, 2000), bem como contribuir para uma maior reflexão sobre o aprendizado e se ele é de fato efetivo por parte dos alunos, de modo a torná-los mais ativos no seu aprendizado (ALAVARSE, 2013).

Os diferentes instrumentos de avaliação podem ser utilizados como poderosas ferramentas para evidenciar as dificuldades que os estudantes apresentam em um determinado tema de uma matéria, nortear o docente sobre o quáo eficiente tem sido a aplicação de suas concepçóes de ensino e aprendizagem (MALDANER, 2013) e a oportunidade de refletir sobre a própria prática.

A pesquisa salientou que a desconstrução dos métodos tradicionais de avaliação é vista pelos estudantes de forma positiva, pois proporciona a deteç̧áo do método de avaliaçáo com a qual eles possuem maior afinidade, minimiza a importância da classificação por notas e enfatiza a reflexão e compreensão dos estudantes sobre o conteúdo ensinado o que permite a sequência da aprendizagem de forma dinâmica (LOCATELLI, 2017).

Ao considerar a utilização do portfólio, uma metodologia ativa, como uma ferramenta alternativa as provas convencionalmente utilizadas, parece ter sido relevante na construção do conhecimento na visão desses alunos. Isso evidencia a importância de se considerar mais de um instrumento para se avaliar os alunos.

A utilização de instrumentos diversos para a avaliaçáo permite que os alunos aprendam a compreender o que é ensinado, por meio da articulaçáo de informaçóes, de forma que esses possam a todo momento repensar seu desenvolvimento (COTTA; 
COSTA; MENDONÇA, 2015). Dessa forma, os alunos se tornam metacognitivos e fazem da avaliação um verdadeiro momento de aprendizagem.

\section{CONSIDERAÇÓES FINAIS}

Após relacionar todos os elementos do presente artigo foi possível perceber como se faz necessária a discussáo do que se entende por avaliaçáo, uma parte essencial do currículo e da prática docente, e como ela impacta a vida de professores e estudantes.

O trabalho elencou diversos componentes sobre avaliação e por meio do questionário aplicado a turma do primeiro ano que cursou a disciplina Química Geral, foi possível perceber que os alunos ainda se encontram muito ligados à percepção quantitativa, classificatória e até mesmo punitiva da avaliação. Isso pode estar associado à forma hierarquizada com que a avaliação pode ter sido incluída em suas vidas, na qual a relevância do ato de ser avaliado e de se autoavaliar não foi priorizada. Entretanto a utilização de uma ferramenta de avaliação alternativa na disciplina, como o portfólio, mostrou-se muito promissora a aprendizagem dos estudantes, uma vez que possibilita a reflexão e uma autoavaliação do seu processo de aprendizagem, o que pode ser um indicativo de possível mudança, ainda que lenta, nas concepçóes sobre avaliaçáo para esses estudantes.

Dessa forma, para transformar a compreensão da avaliação, será imprescindível que os professores repensem seus aprendizados e questionem se não conduzem suas aulas de maneira mecânica e se são capazes de engajar os alunos no aprendizado. Assim como, se os conteúdos ministrados aos alunos são passados de forma coerente, com critérios bem definidos, possibilitando aos estudantes a oportunidade de alcançar uma autonomia em seus estudos que os beneficiará por toda a vida acadêmica.

\section{REFERÊNCIAS}

ALAVARSE, O. M. Desafios da avaliação educacional: ensino e aprendizagem como objetos de avaliaçâoo para a igualdade de resultados. Cadernos Cenpec. São Paulo. v.3. n.1. p.135-153, 2013. Disponível em http://cadernos.cenpec.org.br/cadernos/index.php/ cadernos/article/view/206 acesso 30 mai.2021.

ALMEIDA, N. L. T. Educação e políticas públicas na cidade. In: DAVID, C.M., et al., orgs. Desafios contemporâneos da educaçáo [online]. São Paulo: Editora UNESP; São Paulo: Cultura Acadêmica. Desafios contemporâneos collection, pp. 33-51, 2015.

ALTARUGIO, M. H.; LOCATELLI, S. W. Os saberes docentes e a formação do bom professor de ciências. Revista Espaço Pedagógico, v. 25, n. 2, p. 364-382, 2018.

Disponível em http://seer.upf.br/index.php/rep/article/view/8169 acesso 30 mai. 2021. 
BIZELLI, J. L. Educação para a cidadania. In: DAVID, C.M., et al., orgs. Desafios contemporâneos da educação [online]. São Paulo: Editora UNESP; São Paulo: Cultura Acadêmica. Desafios contemporâneos collection, pp. 19-31, 2015.

BRASIL. Base Nacional Comum Curricular. Brasília: MEC, 2017.

COTTA, R. M. M.; COSTA, G. D.; MENDONÇA, E. T. Portfólios crítico-reflexivos: uma proposta pedagógica centrada nas competências cognitivas e metacognitivas.

Interface (Botucatu), v.19, n.54, p. 573-88, 2015. Disponível em https://www.scielo.br/j/ icse/a/T4LDVm3fZKsV9rWQGVmPZVC/?lang=pt\&format=pdf acesso 30 mai. 2021.

DIAS, E.; PINTO, F. C. F. Educação e Sociedade. Ensaio: aval.pol.públ.Educ. Rio de Janeiro, v. 27, n.104, p. 449-454, 2019. Disponível em https://doi.org/10.1590/s010440362019002701041 acesso 30 mai. 2021.

GADOTTI, M. Perspectivas atuais da educação. São Paulo Perspec. São Paulo, v.14, n. 2, p. 03-11, 2000. Disponível em https://doi.org/10.1590/S0102-88392000000200002, acesso 30 mai. 2021.

HEBERLE, M. A avaliação da aprendizagem: um olhar a partir do léxico dos alunos.

Revista Signos, v. 35, n. 2, 2014. Disponível em: http://www.univates.br/revistas/index. php/signos/article/view/772/762 acesso 12 jun. 2020.

LOCATELLI, S. W. Metacognição. Tópicos de metacognição: para aprender e ensinar melhor. Editora Appris, 2014.

LOCATELLI, S. W. A percepção de graduandos acerca de um processo avaliativo em práticas de ensino de Química: é possível avaliar de forma diferente?.Revista Docência do Ensino Superior, v. 7, n. 2, p. 13-33, 2017. Disponível em https://periodicos.ufmg.br/ index.php/rdes/article/view/2241 acesso 30 mai.2021.

LUCKESI, C. C. O que é mesmo o ato de avaliar a aprendizagem? Disponível Pátio On-line. Pátio. Porto alegre: ARTMED. Ano 3, n. 12, 2000.

MACENO, N. G.; GUIMARÁES, O. M. Concepçóes de ensino e de avaliação de professores de química do ensino médio. Revista Electrónica de Enseñanza de las Ciencias. v. 12, n. 1, p.24-44, 2013. Disponível em http://reec.uvigo.es/volumenes/ volumen12/REEC_12_1_2_ex648.pdf acesso 30 mai. 2021.

MALAFAIA, G.; RODRIGUES, A. S. L. Uso Da Teoria Das Inteligências Múltiplas No Ensino De Biologia Para Alunos Do Ensino Médio. SaBios: Rev. Saúde e Biol., v.6, n.3, p.08-17, 2011. Disponível em http://www.revista.grupointegrado.br/sabios/ acesso 30 mai. 2021.

MALDANER, O. A. A avaliação escolar em química. Em MALDANER, O. A. A formação inicial e continuada de professores de química. 2013, p. 254 - 265.

MARINHO, J. C. B.; CALCAGNO, S. C.; DA SILVA, J. A. Estado da Arte sobre avaliação no Ensino de Ciências. Revista Thema, v. 15, n. 2, p. 653-671, 2018. 
Disponível em http://periodicos.ifsul.edu.br/index.php/thema/article/view/847 acesso em 30 mai. 2021.

NOGARO, A.; ECCO, I. Postulaçóes provocativas sobre aprendizagem da avaliação escolar como processo formativo. Rev. Horizontes, v. 33, n. 1, p. 113-122, 2015. Disponível https://revistahorizontes.usf.edu.br/horizontes/article/view/137/84 acesso 30 mai. 2021.

NÖRNBERG, N. E.; FORSTER, M. M. S. Ensino Superior: as competências docentes para ensinar no mundo contemporâneo. Rev. Docência Ens. Sup., v. 6, n. 1, p. 187-210, 2016. Disponível em https://periodicos.ufmg.br/index.php/rdes/article/view/2095 acesso 30 mai. 2021.

PARANHOS, R.; FIGUEIREDO FILHO, D. B.; ROCHA, E. C.; SILVA JÚNIOR, J. A.; FREITAS, D. Uma introdução aos métodos mistos. Sociologias, v.18, n.42, 384-411, 2016. Disponível em https://www.scielo.br/j/soc/a/WtDMmCV3jQB8mT6tmpnzkKc/ abstract/?lang=pt acesso 30 mai. 2021.

PERRENOUD, P. Avaliação: da excelência à regularizaçáo das aprendizagens: entre duas lógicas. Porto Alegre, Artmed, 1998. Disponível em: www.e-disciplinas.usp.br acesso 30 mai. 2021.

RAMOS, R. L; ARGOLO, H. S. As concepções de avaliação de estudantes dos cursos de pós-graduação em docência: expectativas, preparação e realidade em sala de aula.

Educaçáo Em Perspectiva, v.9, n.3, p. 714-733, 2018. Disponível em https://periodicos. ufv.br/educacaoemperspectiva/article/view/7074 acesso 30 mai. 2021.

RIBEIRO, C. Metacognição: um apoio ao processo de aprendizagem. Psicol. Reflex. Crit., Porto Alegre, v. 16, n. 1, p. 109-116, 2003. Disponível em https:/www.scielo.br/ pdf/prc/v16n1/16802.pdf acesso 30 mai. 2021.

TREAGUST, D.; DUIT, R.; NIESWANDT, M. Sources of students' difficulties in learning Chemistry. Educación Química, v. 11, n. 2, 2000.

VIDAL, P. H. O.; PORTO, P. A. Representações químicas e a História da Ciência em sala de aula. História da Ciência e Ensino: Construindo interfaces, v.10, p. 70-84, 2014. Disponível em https://revistas.pucsp.br/index.php/hcensino/article/view/18288 acesso 30 mai. 2021.

ZABALA, A. A avaliação. Em ZABALA, Antoni. A prática educativa. 1998, p. 195 210. 